\title{
Urdimento
}

Revista de Estudos em Artes Cênicas

E-ISSN: 2358.6958

\section{O mesmo, só que diferente: o Teatro e a "assombração"}

Marvin Carlson

Tradução: Evelyn Furquim Werneck Lima

\section{Para citar este artigo:}

CARLSON, Marvin. O mesmo, só que diferente: 0 Teatro e a "assombração". Trad. Evelyn Furquim Werneck Lima. Urdimento, Florianópolis, v. 2, n. 38, ago./set. 2020.

DOI: http:/dx.doi.org/10.5965/14145731023820200045 
O mesmo, só que diferente: o Teatro e a "assombração"

Marvin Carlson ${ }^{1}$

Tradução: Evelyn Furquim Werneck Lima²

\begin{abstract}
Resumo
O texto da conferência proferida por Marvin Carlson em outubro de 2019 na Unirio, cuja tradução apresento aqui, explora uma temática significativa para aqueles que estudam a recepção teatral. Conduzindo o leitor por diferentes espetáculos e variados grupos teatrais ao longo da história, o autor discute e comprova que, devido a certas características únicas do teatro como atividade humana, esta arte opera uma dinâmica universal de cognição e experiência, fundamentada na memória de experiências anteriores colocadas em justaposição com as novas, processo que ele intitula de ghosting e que traduzi por "assombração".
\end{abstract}

Palavras-chave: Recepção teatral. Cognição. Memória. "assombração".

\title{
The Same. Only Different: Theatre and Ghosting
}

\begin{abstract}
The conference paper addressed by Marvin Carlson in October 2019 at Unirio, whose translation I present here, examines a significant subject for those who study theatrical reception. Leading the reader through different productions and various theatre groups throughout history, the author discusses and proves that, due to certain unique characteristics of theatre as a human activity, this art operates a universal dynamic of cognition, based on the memory of previous experiences juxtaposed with the new ones. The author calls this process ghosting.
\end{abstract}

Keywords: Theatrical reception. Cognition. Memory. Ghosting.

\footnotetext{
Marvin Carlson é Ph. D. in Drama e Teatro pela Universidade de Cornell. Atualmente é o Sidney E. Cohn Distinguished Professor de Teatro, Literatura Comparada e Estudos do Oriente Médio na City of New York University. Sua obra abrange principalmente a história e teoria do teatro do século XVIII ao século XXI. Ele recebeu o ATHE Career Achievement Award, o George Jean Nathan Prize, o Barnard Hewitt Prize, o George Freedley Award, o Edgar Rosenblum Award, o Oscar G. Brockett Prize, e um Guggenheim Fellowship. Seu livro mais conhecido no Brasil é Teorias do Teatro (Editora UNESP, 1997), traduzido em sete línguas. Seu livro The Haunted Stage de 2001 recebeu o prêmio Callaway.

${ }^{2}$ Coordena o Laboratório de Estudos do Espaço Teatral e Memória Urbana desenvolvendo trabalhos sobre arquitetura teatral e cenografia. É professora Titular do Programa de Pós-graduação em Artes Cênicas e doutora em História Social (UFRJ com estágio doutoral na Ecole des Hautes Etudes en Sciences SocialesParis) e pós-doutora (Paris X- 2003 e Collège de France-2011). É Pesquisadora 1- B do CNPq. evelynfwlima@yahoo.com.br
} 
Nota da tradutora

A presente tradução refere-se à conferência proferida pelo Professor Marvin Carlson no International Seminar Marvin Carlson: Theatre, Memory and Culture, ocorrido na Universidade Federal do Estado do Rio de Janeiro - Unirio de 10 a 12 de outubro de 2019 e intitulada "The Same. Only Different: Theatre and Ghosting". Como fiz a tradução consecutiva durante a conferência, e verifiquei que despertou grande interesse da plateia que lotou a Sala Paschoal Carlos Magno do Centro de Letras e Artes da Universidade Federal do Estado do Rio de Janeiro, estou publicando o texto em português na Urdimento, no sentido de ampliar o tema da discussão, relevante para os estudos da recepção teatral na Academia. O principal argumento do renomado estudioso do teatro é defender que "a dinâmica universal de cognição, experiência e memória opera no teatro de uma maneira substancialmente diferente de como opera em outras atividades humanas, mesmo nas outras artes, devido a certas características únicas do próprio teatro como uma atividade humana". A palavra que mais se aproxima do termo ghosting na língua portuguesa a meu ver é "assombração". Além de manter o estilo do autor, acrescentei pequenas notas para facilitar o entendimento dos diferentes exemplos citados pelo conferencista em diversas temporalidades. Como não disponho da autorização para o uso das imagens, a tradução restringe-se ao texto, de grande significado para aqueles que investigam processos de recepção teatral.

Boa leitura!

Evelyn Furquim Werneck Lima 
Quando, em 1990, a plateia do Teatro Richard Rodgers em Nova York assistiu ao Accomplice (Cúmplice) - ,uma nova peça de Rupert Holmes, anunciada como "thriller de comédia", este termo acabou bem estabelecido como sendo uma forma particular de peça de suspense do final do século XX, baseado na tradicional história de detetive, mas com uma dose significativa de humor negro, truques dramáticos e disfarces. Os sucessos populares da Broadway: Sleuth (Jogo Mortal) ${ }^{4}$ em 1970 e Deathtrap (Armadilha Mortal) em 1978 foram transformados em filmes de sucesso e criaram esse subgênero, que permaneceu popular em Nova York pelo resto do século 5 .

A proposta prometia um cenário muito semelhante ao dessas duas peças inspiradoras já citadas, ou seja, uma sala de estar de classe alta, em "Dorping Mill, a distante residência de campo de Derek e Janet Taylor na colina", e a cortina se abria para revelar um interior elegante, embora um pouco rústico, cheio dos detalhes cênicos peculiares à maioria desses dramas. A ação começa quando um ator - aparentemente o homem dono da casa que retorna do trabalho, entra pela porta principal, tira o casaco e o chapéu, e dirige-se a uma pequena mesa lateral para preparar uma bebida.

Toda essa pantomima parece perfeitamente normal até que o ator se vira para a plateia e dirige aos espectadores as primeiras falas da peça, que são: "É exatamente assim que todas essas peças começam, não é? Dorping Mill, a residência de Derek e Janet Taylor na antiga colina de...” e continua repetindo exatamente a didascália do texto que ele acabou de apresentar. ${ }^{6}$

É claro que existem muitas outras surpresas deste tipo durante a peça, mas quero parar por aqui e fazer uma básica pergunta analítica. Qual é o truque que

\footnotetext{
${ }^{3}$ Accomplice, do dramaturgo Rupert Holmes foi a vencedora do Edgar Award 1991 como a melhor peça dos Escritores de Mistério da América. A peça se inicia como um thriller inglês tradicional em uma casa de campo na qual a esposa e seu amante planejam assassinar o marido. (Nota da Tradutora)

${ }^{4}$ Sleuth foi exibido em filme no Brasil como Jogo Mortal e em Portugal como Autópsia de um Crime. (Nota da Tradutora)

5 Para maior conhecimento da história e dos estudos deste gênero, consultar o livro, Deathtraps: The Postmodern Comedy Thriller. Bloomington: Indiana University Press, 1993, de Marvin Carlson.
}

${ }^{6}$ Consultar o texto integral da peça em Rupert Holmes, Accomplice. New York: Samuel French, 1991. 
existe nesta peça e porque ele funciona, uma vez que a resposta nos conduz diretamente ao fenômeno que quero discutir nesta conferência.

Para que essa sequência tenha seu efeito surpresa adequado, o autor deve fazer uma suposição crítica sobre os espectadores, e isso é supor que eles tenham assistido a um suficiente número de peças similares ao Accomplice (Cúmplice) para reconhecer imediatamente as convenções desse gênero. Observem o apelo inicial a esse conhecimento da plateia: "É exatamente assim que todas essas peças começam, não é?" É claro que todas essas peças não incluem Hamlet, Tartuffe ou Medeia, nem mesmo a Casa de Bonecas ou A morte de um caixeiro viajante, mas apenas peças de um tipo muito particular, incluindo as conhecidas peças Sleuth (Jogo Mortal) e Deathtrap (Armadilha Mortal), e Holmes assume que toda ou a maioria de seus espectadores entenderiam imediatamente isso, sem referência mais específica do que "essas peças".

Por que este diretor pode adotar esse método? A resposta envolve uma espécie de paradoxo sobre a natureza das plateias de teatro e, de fato, do público em geral em quase todos os eventos. Embora, teoricamente, a plateia possa ser composta por uma assembleia bastante aleatória de indivíduos, na verdade isso nunca é o caso. Apesar de não podermos prever a formação ou a experiência passada de qualquer espectador, podemos deduzir um certo número de características sobre qualquer plateia em geral. Entre elas, a mais importante é que a grande maioria desses espectadores já experimentou outro tipo de evento semelhante àquele do qual está participando naquele momento.

A maioria dos frequentadores de concertos já participou de muitos outros concertos, a maioria dos visitantes de museus de arte já fez muitas outras visitas semelhantes no passado, e a mesma constatação é verdadeira para o público de teatro.

O ponto relevante da compreensão e apreciação de qualquer uma dessas experiências é a memória de experiências anteriores colocadas em justaposição com as novas. O que estamos descrevendo aqui é uma operação básica de cognição, não apenas nas artes, mas em todas as experiências humanas. Memória 
e compreensão são inseparáveis e muitas das atividades foram buscadas conscientemente, tais como as experiências artísticas, que selecionamos porque podemos levar conosco um repertório já acumulado de memórias de eventos semelhantes que podemos utilizar para entender e apreciar a nova experiência.

O que quero discutir nesta conferência é como essa dinâmica universal de cognição, experiência e memória opera no teatro de uma maneira substancialmente diferente de como opera em outras atividades humanas, mesmo nas outras artes, devido a certas características únicas do próprio teatro como uma atividade humana. Voltemos novamente à abertura não convencional do Accomplice, que eu argumentaria que é uma experiência apenas peculiar ao teatro.

Imaginem, por exemplo, que, como espectadores, não estamos sentados em um teatro da Broadway, mas em alguma importante sala de concertos, como o Carnegie Hall, nas proximidades da Broadway. Estamos ali reunidos para ouvir a estreia de uma nova sinfonia, mas de uma sinfonia tal como fomos preparados para ouvir, ou seja, que siga um estilo estabelecido, por exemplo, o estilo de Beethoven.

A orquestra começa a tocar a peça musical, nitidamente naquele estilo, mas, alguns momentos após o início, o primeiro violinista para de tocar, assim como o fazem os demais músicos e ele vem para a frente do palco para se dirigir diretamente à plateia, dizendo: "É exatamente assim que todas essas sinfonias começam, não é?" Mesmo na era de John Cage, tal ocorrência permanece bastante improvável. Por que os espectadores nova-iorquinos em um teatro da Broadway podem aceitar tal desvio de percepção, enquanto uma plateia igualmente sofisticada, a alguns quarteirões de distância, não aceitaria uma mudança semelhante em uma apresentação musical?

A resposta está na relação específica com a realidade que o teatro não compartilha com nenhuma outra arte. Os teóricos do teatro desde que os gregos reconheceram a relevância da mimesis para o teatro, que também é uma arte baseada na imitação, mas igualmente relevante é reconhecer que o teatro, ao 
contrário das outras artes, realiza essa imitação usando elementos reais - corpos reais imitando outros corpos, cadeiras tangíveis imitando outras cadeiras, trajes verdadeiros imitando outros trajes.

Essencial à experiência teatral é o conhecimento de que, mesmo enquanto imaginamos acreditar na realidade do personagem Hamlet, também estamos cientes em algum nível de que o que estamos assistindo é um ser humano vivo que não é verdadeiramente Hamlet, e pode muitas vezes ser um ator que conhecemos de outros papéis. É por isso que, ao longo da história do teatro, os atores conseguiram deixar o ambiente do palco e falar diretamente com o público em diferentes ocasiões, sem, contudo, destruir a experiência teatral.

Na tentativa de esclarecer essas múltiplas posições, os teóricos semióticos às vezes referem-se de três maneiras diferentes pelas quais um ator no teatro era avaliado - (i) como ator, ou seja, como o indivíduo real, no caso, John Gielgud, (ii) desempenhando um papel como personagem, no caso Hamlet, a pessoa criada por Shakespeare e, (iii) como uma personificação particular de Hamlet criada por Gielgud, que é diferente da do Hamlet de qualquer outro ator e também diferente de qualquer outro papel desempenhado pelo próprio Gielgud. ${ }^{7}$

Embora raramente pensemos sobre esses vários níveis de realidade, a menos que a encenação nos chame a atenção para esses níveis, eles sempre fazem parte da experiência, especialmente porque, como já observei, a maioria dos espectadores de qualquer plateia de teatro já traz a memória de muitas experiências teatrais anteriores.

Assim, se um ator conhecido como Gielgud aparecer em uma nova montagem de uma peça frequentemente encenada como Hamlet, é quase certo que a maior parte da plateia assistirá à sua apresentação lembrando não apenas de outras encenações desse ator em outras montagens, mas também de outras montagens dessa mesma peça com outros atores. Ao assistir a uma peça, somos sempre em certa medida afetados pelas lembranças de outras peças, que cercam nossas experiências atuais como "fantasmas". Por essa razão, eu designei essa 
parte inevitável do processo de recepção no teatro de “assombração", e considero que toda nova encenação, em algum grau ou outro, é assombrada por tais fantasmas. (Carlson, 2001, p. 7-8).

Entre todas as formas de arte, o teatro está particularmente envolvido com esse tipo de experiência por várias razões. Primeiro, o teatro opera em uma ampla variedade de níveis, empregando uma ampla variedade de materiais e metodologias para obter seus efeitos, e qualquer um deles oferece a possibilidade de "assombração" do passado. Em segundo, o teatro é mais empenhado do que outras artes em reutilizar os mesmos materiais físicos e não físicos em combinações mutáveis, sempre abrindo a possibilidade de que esses materiais em novas combinações despertem, entretanto, lembranças de seu uso anterior.

Como observei, esse fenômeno é particularmente rico no caso dos atores, o elemento mais proeminente no teatro. Deve-se considerar, no entanto, que o teatro envolve o ator com uma grande variedade de outros objetos que também podem ocupar um lugar no mundo físico fora do palco, acionando memórias e associações na mente do público, pelo fato de poderem ser usados repetidamente seja na mesma montagem ou em diferentes montagens. Um objeto específico um imóvel característico, uma cadeira, um traje - podem, tal como o ator, evocar os fantasmas de suas aparições anteriores, no palco e fora dele.

Por lei, os teatros profissionais de Nova York são obrigados a não reutilizar adereços ou indumentária no intuito de proteger os negócios daqueles que produzem esses objetos, porém, em teatros menores e ao longo da maior parte da história do teatro, os edifícios teatrais mantêm depósitos de tais dispositivos cênicos e os usam com frequência em múltiplas montagens. Um dos principais grupos experimentais dos Estados Unidos, o Wooster Group, tornou-se especialmente associado a essa dinâmica, recuperando objetos individuais específicos como adereços recorrentes, tal como um mata-moscas vermelho muito peculiar em uma variedade de diferentes encenações que não têm nenhuma relação entre si, mas incentivando a plateia a conectar essas montagens como diferentes experimentos deste mesmo grupo específico. (Carlson, 2001, p. 170). 
Esse elemento de repetição individual sugere uma ampla gama de outros elementos recorrentes que condicionam profundamente a experiência de uma plateia que assiste a uma montagem do Wooster Group. A maior parte do passado e do presente do teatro mundial, tradicional e experimental, foi criada por grupos de atores mais ou menos estáveis, dos quais o Wooster Group é um importante exemplo contemporâneo. Esse arranjo é particularmente encorajador para a “assombração", já que os espectadores habituais (e a maioria dos grupos depende muito desses espectadores) trará consigo para as novas montagens, não apenas lembranças de atores individuais, mas de grupos e associações.

Se uma plateia francesa assistisse a uma nova peça de Molière na década de 1660, e a cortina subisse deixando à vista os atores La Grange e M Mle De Brie, nenhuma palavra precisaria ser dita antes que a plateia reconhecesse por experiência anterior com estes atores, com esta companhia e com este dramaturgo, que aqueles eram dois amantes de longa data, cuja separação temporária e subsequente união seriam o tema daquela comédia. (Carlson, 2001, p. 111).

A composição e o modo de operar da companhia de Molière seria representativa dos grupos teatrais em todo o mundo ocidental pelos próximos dois séculos e refletiu uma característica do teatro ocidental que pode ser rastreada pelo menos até a Idade Média e, possivelmente, até a antiguidade clássica. Desde os tempos romanos, o teatro tem sido amplamente produzido por companhias de atores mais ou menos estáveis, muitas vezes inter-relacionadas e, à medida em que o teatro se tornava mais literário, um dramaturgo específico escrevia novas peças para o grupo. Portanto, nos tempos clássicos, o teatro ocidental estabeleceu um conjunto específico de relações entre personagens, resultando em estruturas de histórias particulares que permaneceram notavelmente estáveis por séculos. Inúmeros elementos no teatro trabalharam para reforçar essa estabilidade e as memórias associadas a ela. Mais notadamente, cada companhia teatral possuía alguns personagens-estereotipados que interpretariam personagens surpreendentemente semelhantes, peça após peça. $\bigcirc$ exemplo mais conhecido disso é a tradição da Commedia dell' arte, que teve uma 
forte influência sobre Molière e outros dramaturgos (Andrews, 2005).

Assim, o público de Molière sabia desde o início que tipo de personagem (o de jovem amante) La Grange interpretaria naquela noite, não apenas por causa de peças anteriores de Molière, mas também de comédias em geral, que desde os romanos se preocupavam com os casos de amor de jovens como La Grange. Um ciclo contínuo foi assim estabelecido. A plateia aguardava e os dramaturgos criavam peças apresentando certos atores em determinados papéis e interrelacionamentos peça após peça, e os atores eram contratados e conhecidos por apresentar um certo tipo de papel, mesmo quando, em alguns casos, envelheciam demais para fazer realisticamente tais papéis. Nesses casos, o poder das lembranças do público de suas apresentações passadas poderia até superar a clara evidência visual de que eles não eram mais jovens amantes inexperientes. Tão bem estabelecida era essa associação entre ator e personagem-tipo que Molière geralmente dava aos atores de famílias bastante diferentes o mesmo primeiro nome, marcando o personagem-tipo - Valère para os jovens amantes interpretados por La Grange, e Marianne para suas eventuais parceiras, interpretadas por De Brie.

Nomes de personagens recorrentes em diferentes peças consistem em uma outra maneira pela qual o teatro tradicionalmente incentiva a memória da plateia e o processo de "assombração". Isso opera de diferentes formas, cada uma das quais tem sido amplamente utilizada pelo teatro. Personagens populares sempre encorajaram dramaturgos e plateias a trazê-los de volta em outras situações, como Beaumarchais fez com Fígaro, ou a rainha Elizabeth I pediu a Shakespeare que fizesse com Falstaff.

A partir do momento em que o popular detetive criado pelo escritor Conan Doyle, Sherlock Holmes, fez a transição da página para o palco, ele ali se estabeleceu tão solidamente que continua até hoje em novas histórias criadas para o cinema e para a televisão. Muitas vezes, esses personagens recorrentes vêm acompanhados, assim como Sherlock, de um mundo inteiro de lugares, adereços, trajes e de outros personagens - o inevitável Watson, é claro, mas também o irmão de Sherlock, Mycroft, sua fiel senhoria, a sra. Hudson, seu arqui- 
inimigo, Moriarty e outros. Personagens como Holmes, Fígaro ou Falstaff podem se transportar para novas aventuras, carregando seu mundo imaginário com eles, um fantasma cercado por um mundo fantasma, porém flexível. O personagem recorrente carrega consigo não apenas os personagens relacionados, mas uma série específica de ações que também, como fantasmas, pairam sobre qualquer nova interpretação. O exemplo mais significativo disso são as incontáveis peças baseadas na mitologia, uma das fontes mais ricas de histórias de teatro, tanto no Oriente quanto no Ocidente.

Nesse sentido, Antígona traz consigo não apenas um conjunto de personagens relacionados - Creonte, Ismênia, Haemon, Eurídice, até os soldados e, em alguns casos, o coro. O pano de fundo da história pode mudar radicalmente - a França sob ocupação alemã, a Argentina durante as "Guerras Sujas”, o Congo sob Joseph Mobutu, ${ }^{10}$ entretanto, as relações e a estrutura de ação permanecem notavelmente estáveis. Antígona desafia a proibição de Creonte contra o enterro de seu irmão e é condenada à morte por sua ação, apesar de seu noivado com o filho de Creonte, Haemon. Haemon comete suicídio, assim como sua mãe enlutada. Portanto, uma recontagem dramática moderna dessa história será, para a maioria das plateias, "assombrada" pelas lembranças não apenas dos vários elementos específicos da história em si, mas pelas lembranças de montagens anteriores, incluindo o original grego, mas também variantes que continuam a ser criadas em todo o mundo. (Mee \& Foley, 2011).

Repetir histórias, repetir corpos, repetir personagens, repetir ações, repetir objetos físicos, tudo isso é vital para a maneira particular como o teatro conta suas histórias e, também, para o tipo de histórias que conta. Talvez, não surpreendentemente, possamos estender esses fantasmas da memória até os lugares nos quais vamos assistir e participar da montagem, ou seja, os próprios

${ }^{8}$ A França esteve sob a ocupação alemã de maio de 1940 a dezembro de 1944, durante a Segunda Guerra Mundial. (Nota da Tradutora)

${ }^{9}$ Guerra Suja na Argentina (1976-1983) foi o regime adotado em meio a ditadura militar argentina caracterizado por violências e torturas. (Nota da Tradutora)

10 Mobutu foi um ditador do Zaire (atual República Democrática do Congo) entre 1965 e 1997. (Nota da Tradutora) 
lugares da performance

Teatros, com frequência, são literalmente "assombrados" na ficção popular, e, muitos teatros mais antigos são conhecidos por abrigarem fantasmas de atores e gerentes do passado (Nicolls, 2014). Mas o público contribui, revisitando frequentemente o mesmo teatro. As lembranças das peças apresentadas ali e a experiência de vê-las naquele mesmo espaço contribuem para a experiência da plateia, principalmente quando o próprio edifício teatral, como costuma ser o caso, torna-se particularmente associado a certos atores, autores ou dramas dramáticos ou ainda a determinadas companhias tais como o Berliner Ensemble de Brecht, a Comédie de Molière ou o Performing Garage do Wooster Group.

Portanto, a partir do momento em que o público entra em um espaço de atuação cênica, ele é imerso em um mundo composto por muitas encenações reais e lembradas de apresentações anteriores ali e em outros lugares. Quanto mais teatro se assiste, mais rica se torna a interação entre uma experiência nova e uma experiência lembrada. Cada nova encenação é diferente e, no entanto, de alguma forma, também é a mesma - e a combinação dessas duas condições está no cerne da recepção teatral.

\section{Referências}

ANDREWS, Richard. Molière, Commedia dell'arte, and the Question of Influence in Early Modern European Theatre, The Modern Language Review, CARLSON, Marvin. Deathtraps: The Postmodern Comedy Thriller. Bloomington: Indiana University Press, 1993.

CARLSON, Marvin, The Haunted Stage: The Theatre as Memory-Machine. Ann Arbor: University of Michigan Press, 2001.

HOLMES, Rupert. Accomplice. New York: Samuel French, 1991.

MEE, Erin B.; FOLEY, Helene P. Antigone on the Contemporary World Stage. Oxford: Oxford University Press, 2011.

NICHOLLS, Edmund, The Haunted History of British Theatres. Londres: InView, 2014. 
VELTRUSKYY, Jiří. The Prague School Theory of Theater, Poetics Today 2:3, 1981.

Recebido em: 07/04/2020

Aprovado em: 11/05/2020

Universidade do Estado de Santa Catarina - UDESC

Programa de Pós-Graduação em Teatro - PPGT Centro de Arte - CEART

Urdimento - Revista de Estudos em Artes Cênicas

Urdimento.ceart@udesc.br 